\title{
Religión: ortodoxia y heterodoxia en la Península Ibérica ${ }^{1}$
}

\author{
LEOPOLDO LLANEZA FADÓN \\ Departamento de Antropología Social \\ Facultad de CC. Políticas y Sociología \\ Universidad Complutense. Madrid
}

\section{INTRODUCCIÓN}

Quisiera mostrar algunos ejemplos de cómo se interrelacionan estos dos conceptos, la ortodoxia y la heterodoxia, en el seno de los movimientos religiosos, especialmente en la península ibérica. Para ello he elegido las monografías de cuatro antropólogos que han trabajado la religiosidad en distintas épocas y desde diversas perspectivas. Los libros citados son los siguientes: Las Visiones de Ezkioga de Willian Christian, Un santo para una ciudad de María Cátedra, El Estigma del Extraño de Joan Prat y Ensaios de Mitologia Cristã de Manuel João Ramos.

Soy consciente de lo difícil y aleatorio que puede resultar realizar una elección de este tipo, aunque la considero significativa por las siguientes razones. En primer lugar, los cuatro son antropólogos reconocidos como especialistas en este campo de estudio. En segundo lugar, las cuatro monografías han sido editadas recientemente, son novedosas, con planteamientos originales y prestan especial atención a la historia. En tercer lugar, las cuatro aportan tesis muy sugerentes sobre el modo de realizar investigaciones en el campo de las actitudes y creencias religiosas, teniendo en cuenta el contexto más amplio en que éstas se producen.

$\mathrm{Y}$ es que es importante resaltar cómo la ortodoxia y la heterodoxia son conceptos flexibles que se diluyen con el paso del tiempo. Pretendo demostrar que estos conceptos, que aparecen inmutables e impregnados de un halo de sustantividad y dogma, son en realidad construcciones humanas y, como tales, están sujetas a los vaivenes que esconden nuestros actos y a las distintas corrientes culturales. La ortodoxia y la heterodoxia son, pues, conceptos cambiantes dotados de una poderosa carga simbólica que, por diversas razones, nos permiten conocer cómo han sido

1 Resumen de la comunicación presentada en el II Congreso de Religiosidad Popular, Andújar, Abril de 1998. 
los hombres, las circunstancias y el orden social de un determinado período histórico.

\section{ORTODOXIA Y HETERODOXIA}

La ortodoxia alude al poder consolidado e institucionalizado que delimita de una manera nítida cuál es el campo de crítica permitido. Una definición clásica es la del Diccionario de la Real Academia de la Lengua (1970) que da como significado: arectitud dogmática o conformidad con el dogma católico" y en su segunda acepción: "conformidad con la doctrina fundamental de cualquier secta o sistemaw. La heterodoxia y el heterodoxo son definidos como discrepancia frente al dogma. Teniendo en cuenta estos dos polos, a continuación voy a resumir algunos de los aspectos más importantes que aparecen en los estudios de los cuatro antropólogos citados.

En Las Visiones de Ezkioga. La Segunda República y el Reino de Cristo $(1997)^{2}$, William A. Christian pone de manifiesto cómo era el mundo deseado por un grupo de personas de extrema sensibilidad religiosa y social en un momento dado. Con estas palabras iniciales del prólogo queda patente la magnitud del acontecimiento que relata:

El 29 de junio de 1931, dos niños del País Vasco español dijeron haber visto a la Virgen María. Esta visión inicial condujo a muchas otras más. De hecho, hubo visiones cada noche durante muchos meses. Alrededor de un millón de personas acudieron, sólo en 1931, al lugar de las apariciones en la pendiente de una colina junto a Ezkioga y la gente comenzó a tener visiones en una veintena de localidades diferentes. Hasta las apariciones a los adolescentes de Medjugorje, en la década de 1980, los videntes de Ezkioga fueron quienes atrajeron un número de personas mayor que cualquier otra aparición del mundo católico.

Christian describe el proceso de las visiones teniendo en cuenta el contexto histórico - la proclamación de la Segunda República-, el contexto social —el advenimiento de una clase social liberal y laica- y la importancia decisiva de los promotores de videntes. Porque fue a través de los videntes como determinados grupos sociales seleccionaron y recompensaron determinadas visiones y por ende a determinadas personas. En los capítulos de su libro dedicados a los "promotores y videntes", Christian reconstruye la manera en que distintas organizaciones socialmente influyentes buscan el apoyo divino - a través de los videntes- y cómo

2 El libro se publicó primero en inglés, con un título algo diferente: Visionaries The Spanish Republic and the Reign of Christ (Berkeley: University of California Press, 1996). 
en ese juego de fuerzas está el reconocimiento y la fama de las visiones en su punto más vulnerable. Y es que, como afirma el autor, se trata de "no entrar en la cuestión de la intervención divina" sino de "entender la parte humana de ese modelo" ${ }^{3}$.

El nacimiento de nuevos mundos religiosos ofrece, a través de los videntes y las visiones, esas características esenciales para ir en contra del dogma imperante y quizá ser al mismo tiempo los elementos más sensibles de la percepción colectiva. De esta manera, el tema del poder se perfila como la lucha existente en toda innovación contra el antiguo orden establecido.

Christian al describir y analizar las estrategias seguidas por unos y otros, logra desentrañar el juego de fuerzas sociales y los intereses que persiguen, mostrándonos qué caracteriza a una sociedad como la de Ezkioga en un momento histórico determinado y cómo esa organización de lo divino se "esparce" por los espacios aledaños. La pequeña localidad de Ezkioga - con sus 550 habitantes en 1931, agrupados en torno a varios caseríos dispersos- tipifica de alguna manera el mundo rural del País Vasco, con una cultura devota caracterizada por su suspicacia hacia el anticlericalismo de las ciudades españolas y por ende hacia los gobiernos progresistas. También en este período histórico asistimos al progresivo encumbramiento de una nueva clase social que tenía en los trabajadores industriales su fuerza principal. Trabajadores - muchos de ellos emigrantes- que se caracterizaban por su militancia anticlerical y por vivir en los nuevos focos de industrialización del País Vasco, siendo los protagonistas de una nueva base económica, opuesta a la rural que, hasta hacía poco, era la hegemónica. No es casual, como indica Christian, que la mayoría de los videntes procedieran de caseríos y no de las villas o ciudades del País Vasco.

Era notorio que las mujeres y niños carecían de poder frente a los adultos varones y los videntes solían ser gente de escasos recursos económicos. Estas manifestaciones de energía y fuerza sobrenatural se personalizaban en los videntes, que eran, a su vez, caracterizados por una inversión de poder. El control y la iniciativa, así como la posibilidad de ascendencia social, pasaron a niños y personas jóvenes solteras que, en algunos casos, lograron a través de su nueva posición y fama acceder a recursos hasta entonces vetados. Christian sugiere que en las "visiones los poderosos y refinados sienten alivio desprendiéndose del poder y poniéndolo en manos de los menos poderosos, aunque sea de manera simbólica" ${ }^{4}$.

3 William Christian, Las Visiones de Ezkioga. La Segunda República y el Reino de Cristo (Barcelona: Ariel, 1997), p. 17.

4 Ibid., p. 266. 
En las preguntas que los creyentes de Ezkioga hacían a la Virgen, y cuyas respuestas en muchos casos deseaban confirmar, está la parte fundamental de ese período ambiguo que son las visiones, en el que existen dudas y en el que la Iglesia —en este caso- no ha juzgado ni intervenido todavía. De esta manera se sabe con más certeza cuáles son los deseos de las personas. Y en el caso de las "Visiones de Ezkioga" quedan descritos con claridad y profusión los modelos de paraíso soñados y sobre todo el carácter que la vida en la tierra debería tener. Estas manifestaciones suponen - como todas las creencias y rituales - un intento de plantear significados generales, en cuyos términos pueda el individuo interpretar su experiencia y organizar su conducta.

La monografía realizada por Joan Prat, El Estigma del Extraño es un estudio de las sectas religiosas. La esencia del análisis se centra en los problemas "relativos al poder" que plantean las relaciones de los ortodoxos con los herejes y cómo la "verdad" de unos se impone a otros por medios perfectamente mundanos y en diversas épocas históricas. Los objetivos que Prat hace explícitos son, por una parte, saber cuáles son los motivos por los que una sociedad tolerante y democrática como la nuestra etiqueta como sectarios a determinados grupos religiosos y con este estigma los deja fuera de sus fronteras sociales, culturales y simbólicas». Y por otra, conocer porqué determinadas personas, "pese a conocer las consecuencias del estigma y los riesgos sociales, culturales y simbólicos que entraña el desafío, deciden hacerse miembros de instituciones caracterizadas como sectas".

Prat incluye una perspectiva histórica para analizar el nacimiento de las sectas religiosas que, a través de los tiempos, han sido marcadas como peligrosas al cuestionar el orden imperante. Así, las actuales sectas aparecen estructuralmente como confesiones religiosas minoritarias que chocan con la sociedad de una forma que recuerda el lugar que en otras épocas tuvieron los judíos, protestantes, masones e incluso los cristianos primitivos. En este aspecto, los ejemplos del surgimiento de las corrientes heterodoxas, cargadas de connotaciones religiosas tales como hereje, cismático, apóstata o infiel, realmente reflejarían relaciones de poder; es decir de "autoridad, de disensión y de rebelión" 5 .

En estas relaciones de poder y autoridad es donde los mecanismos de estigmatización alcanzan su mayor relevancia. Como constata Prat, estos mecanismos han estado presentes desde siempre, cumpliendo su objetivo último: marcar a un grupo, normalmente minoritario y nuevo, como cul-

5 Joan PRAT, El estigma del extraño. Un ensayo sobre sectas religiosas (Barcelona: Ariel, 1997), p. 36. 
pable de las desgracias que puedan afectar a la sociedad. Para ello se emplean los medios más eficaces desde la posición social mayoritaria. Nuevos conceptos, como "lavado de cerebro", han sido utilizados para juzgar el comportamiento "anómalo" de los integrantes de una secta y, de esta manera, exonerar en gran medida al individuo del comportamiento determinado como errático. Y para ayudar a esa "Víctima involuntaria", como es considerado el sectario, surge la medicalización progresiva de los movimientos antisectarios.

Prat propone una orientación metodológica para subrayar la importancia del estudio antropológico de las sectas. Así, cualquier comunidad religiosa puede ser considerada como un amicrocosmos cargado de significados y muy diferenciado del exterior, lo que le acerca al ideal de estudio antropológico más tradicional, convirtiéndose así en una cultura marginal y exótica, respecto de la cultura del investigador, que suele además pertenecer a la cultura hegemónica" ${ }^{6}$. En el estudio resalta el papel fundamental de la participación en los rituales y analiza los procesos de conversión, la parte central de los mecanismos de estigmatización.

Haciendo especial hincapié en la definición circular de James y en el modelo causal propuesto por Lofland y Stark, son sin embargo las aportaciones de Turner las más significativas - con sus conceptos de liminalidad y communitas - para el estudio de los procesos iniciáticos asociados a los "ritos de paso" que tan magistralmente describió Van Gennep en 1909. De las tres fases que componen un "rito de paso" - separación, liminalidad e integración- Prat presta especial atención a la fase central.

Turner ha utilizado este concepto de limen para referirse a la gente que está en el umbral, es decir a los neófitos o iniciados, que precisamente por su nueva condición han dejado de ser lo que eran para convertirse en otra cosa que aún no son. En esta situación, están «entre lo uno y lo otro" tal como lo describió el propio Turner. Como sujetos en fase liminal, son obligados a despojarse de todas las reglas asociadas a su primera socialización para asumir nuevos parámetros que nada tienen que ver con los anteriores. En este estado los individuos suelen ser percibidos desde el contexto global como peligrosos y contaminados. En la fase liminal los sujetos suelen vivir una solidaridad intensa, con una relación tendente a la igualdad y al compañerismo. La estructura que se opone a la communitas, es el otro modelo de interacción propuesto por Turner. En éste, la sociedad se presenta como un sistema estructurado, diferenciado y jerárquico. Y no cabe duda de que, desde esta perspectiva, la

\footnotetext{
6 Ibid., p. 83
} 
communitas debe ser limitada a unos espacios y tiempos concretos. La communitas sólo puede unir a las personas momentáneamente, es tolerada como una fase, pero jamás como una condición permanente.

Prat, al asociar las iniciaciones de los grupos sectarios con las realizadas por otros grupos sociales —entidades militares, órdenes religiosas tradicionales, etc.- pone de manifiesto cómo su similitud es estructuralmente incuestionable. Lo que cambia de forma radical es el nivel de respaldo social del que gozan los unos y los otros ${ }^{7}$.

La falta de respaldo social estaría en el origen del no reconocimiento del proceso iniciático. Entonces, las características estructurales de la fase liminal se convierten en destructivas. Frente a las enseñanzas iniciáticas surge el "lavado de cerebro", los aspectos totalitarios de la institución son descritos como voraces y rapaces. Los elementos ligados a una disciplina férrea, típica de los procesos liminales, son contemplados como las extravagancias de unos gurús sin escrúpulos.

En el fondo es la opción de un sujeto por una alternativa no prevista la que pone en guardia a la ortodoxia cultural vigente, y "la sociedad castiga su desafío imponiéndole una marca: La del estigma del extraño" 8 .

La religión puede ser entendida como un fuerza transformadora de primera magnitud. Cambia las memorias, los cuerpos y las mentes de los individuos. Es, hasta cierto punto, un ataque frontal a la organización social. Desdibuja las fronteras políticas, sociales y culturales. Puede hacer que un devoto adopte costumbres orientales — budistas, Hare Krisna- y trastoca las fronteras culturales, difuminando el concepto de tradición. Para Jean y John Comaroff la religión no sólo no es la vuelta a la tradición sino el motor de la revolución.

María Cátedra con su monografía Un santo para una Ciudad intenta mostrar cómo se construye simbólicamente una ciudad a través del estudio de su primer santo y patrón - San Segundo- y porqué Ávila es la ciudad de los santos.

La figura de San Segundo - patrón de la ciudad, Varón Apostólico y primer obispo- es objeto de controversia desde la época de su invención y descubrimiento. Y esta controversia es una llave que nos introduce en los escenarios de los sucesos que afectaron a la vida castellana en 1520 con la "revolución de los comuneros". Revolución que ilumina las claves en la construcción social de San Segundo como una figura de poder.

Para analizar el contexto, la autora establece las dimensiones de carácter cultural, simbólico y político que han acompañado a las sucesivas

\footnotetext{
7 Ibid., p. 195.

$8 \quad$ Ibid., p. 196.
} 
reapariciones de San Segundo en Ávila. Cátedra ha escogido tres momentos significativos desde distintos ángulos y épocas. En primer lugar está el significado actual, con la voz del santero que ha vivido en la ermita durante los últimos 20 años. En segundo lugar, realiza una contextualización histórica en uno de los momentos más significativos de Ávila en el siglo XVI, a través de la obra de Antonio de Cianca y, por último, refleja la disputa entre dos clérigos unos años antes de la Guerra Civil. San Segundo es el medio utilizado para organizar y comprender cuál es la composición de fuerzas sociales que está en juego en la ciudad.

Al igual que San Segundo, Santa Paula Barbada es algo más que una nueva santa en la ciudad. En este caso la historia narra cómo una campesina humilde que nació cerca de Ávila —en la aldea de Cardeñosavio crecer su barba para engañar a un caballero que pretendía violarla cuando visitaba la ciudad. La compañera de San Segundo en la ermita ha sido prácticamente olvidada en las mentes de los ciudadanos de la Ávila contemporánea, pero forma parte de la estructura cultural de la ciudad, como enlace de lo que se ha llamado la Gran Tradición y la Pequeña Tradición. Santa Barbada, que es un contrapunto al obispo que encarna la autoridad doctrinal, está caracterizada por su ascetismo y su ligazón con el mundo campesino.

Santa Barbada - al igual que San Segundo- es una figura desconcertante en la ciudad de los santos. Y el estudio de sus sucesivas reapariciones en las estructuras del orden social de Ávila, demuestra, en este ensayo de Cátedra, cómo son figuras de poder, de oposición al poder y el reflejo de los diferentes grupos de la ciudad.

Cuando San Segundo es descubierto, alrededor de 1519, Ávila cuenta con una nueva clase social en ascenso, que está demandando un reconocimiento de su posición social. Los cofrades de San Sebastián, descubridores del sepulcro en su ermita —-situada en la periferia-, se oponen al poderoso cabildo, impidiendo el proyectado traslado del santo a la catedral. Cuando esto sucede en 1594 - más de 70 años después- queda reflejada la paulatina pérdida de poder de los cofrades. Pero en el momento en que San Segundo es descubierto, existen varios métodos alternativos de adquirir influencia y estatus por parte de personas ricas y cristianos nuevos e intentar con ello resolver su frustración por su falta de poder político: "uno de estos medios es el control de importantes símbolos e instituciones religiosas: la posesión del cuerpo del primer obispo no era, desde luego, una bagatela" ${ }^{9}$. Esta manera de obtener estatus y justicia indirectamente no significa

9 María CÁTEDRA, Un santo para una ciudad. Ensayo de antropología urbana (Barcelona: Ariel, 1997), p. 141. 
que no se exigiera de forma directa. De los cinco patronos de San Sebastián que descubren el cuerpo de San Segundo, tres participaron en el movimiento comunero y uno de ellos fue "exceptuado". Los tres patronos eran comerciantes de telas que aparecen en las listas aportando las mayores contribuciones en las alcabalas. En una de las zonas semiperiféricas de esta ciudad amurallada, con un $80 \%$ de la población activa dedicada a la transformación textil y de curtidos, es donde se ubicaba la ermita que guardaba el cuerpo de San Segundo.

La cofradía se convierte en una institución clave en este proceso. Estas agrupaciones profesionales de los artesanos muestran un fuerte sentido corporativo y están ligadas a la religión y al culto de los santos. San Segundo responde al modelo de poder establecido en diferentes épocas, pero especialmente en el siglo xvI. Es el del obispo fundador, prototipo de la cristianización de la península ibérica y que cumple con el ideario, tanto culto como popular, del santo patrono; es decir, con la idea de la comunidad de representarse a sí misma en dicha veneración. Uno de los aspectos más llamativos en la obra realizada por Cátedra, es el "paso" del poder desde la comunidad al Estado Moderno. Para ello estudia uno de los sectores menos conocidos: el de los burgueses y artesanos. Las competencias municipales, que eran prácticamente universales, van pasando poco a poco y en términos políticos a manos del rey y San Segundo no es ajeno a este movimiento. El santo se convierte en un símbolo de poder, de salud y de riqueza. En el trasfondo hay una lucha por el poder, que se evidencia de manera significativa en el movimiento del santo por el entorno urbano de la ciudad. Tal como sugiere Cátedra, "los santos [...] son 'como la gente' y están envueltos en una interacción dinámica con sus estructuras internas y externas. Más que 'de dónde vino' es 'dónde fue', cuáles son las idas y venidas de sus huesos a través de la ciudad ${ }^{10}$.

El ensayo de Cátedra muestra cómo un santo de origen campesino, humilde, situado a las puertas de la ciudad y perteneciente a una cofradía local se convierte en una figura central en la ciudad de los santos. De la ermita a la catedral se traza el espacio que refleja la pérdida de poder y que delimita simbólicamente dos lugares diferentes que suponen ideas contrapuestas del paisaje urbano, grupos antagónicos a pesar del vínculo de mediación que implica la presencia de San Segundo.

La monografía del portugués Manuel João Ramos, Ensaios de Mitologia Cristã estudia la figura del Preste Juan de las Indias. No es sólo un trabajo de interpretación etnográfica, basado en las fuentes de los escritores jesuitas sobre Etiopía y de los viajeros medievales —como Marco Polo-, es

${ }_{10}$ Ibid., p. 203. 
una exploración de los límites, de las fronteras internas de la lógica dual; esa lógica que la tradición antropológica concibe como el propio fundamento de la actividad simbolizadora del hombre en una sociedad.

Esta "exploración de la lógica dual" se produce en torno a la figura legendaria del Preste Juan, que encarnaba los ortodoxos deseos de la cultura occidental de un Rey de Reyes cristiano en el lejano Oriente. La leyenda del Preste Juan se refiere a un todopoderoso Rey que con una edad de 1.000 años gobierna una sociedad perfecta llena de riquezas espirituales y económicas. El poder simbólico de esta figura se muestra en continuas reapariciones a lo largo de la historia, en algunos casos con detalles contradictorios, que es lo que Ramos ha denominado areversibilidad simbólican: es decir, esa capacidad dada por los hombres a sus símbolos que hace que se diluyan con el tiempo, y, con ellos, los conceptos de ortodoxia y heterodoxia implícitos en la lógica dual que sirve de ordenación del mundo conocido en la época histórica del Preste Juan.

Ramos establece una comparación de la Carta del Preste Juan -elemento de análisis fundamental a lo largo de toda su obra- con el texto del Apocalipsis, lo que fundamenta una identificación "cristomimética" del soberano indiano y encuadra sus características de incorruptible e indestructible. Una comparación de la Carta del Preste Juan con el Libro de Alexandre realza una imagen de un Rey que unifica Oriente y Occidente, a la vez que sus detalles más personales - vestido, vivienda - se forman de la oposición entre lo bueno y lo malo. Estas categorías dan paso a una descripción maravillosa en la que los elementos extraordinarios tienen una importancia esencial. Animales y plantas imaginarios están presentes en la construcción de una realidad cristiana de Oriente. La figura del Preste Juan es enlazada con la mentalidad del pueblo conquistador que desea tener un personaje unificador y protector.

A lo largo de cinco siglos, la transformación de la imagen del Preste Juan está condicionada por la acumulación de informaciones geográficas y etnográficas, no implicando el abandono puro y simple del modelo literario inicial - presentado en la Carta como un soberano con características globalizadoras al ser Rey de Reyes y humilde presbítero. En vez de eso "se produce un delicado reajuste en el interior de un cuadro sociológico, donde lo salvaje - lo humano menos la razón - se relaciona con la utopía - lo humano menos lo animal— ${ }^{11}$.

Y es que la Carta del Preste Juan - que no dispone de mecanismos narrativos que soporten en extensión la caracterización de su mun-

11 Manuel João RAmos, Ensaios de Mitologia Cristã (Lisboa: Assirio \& Alvim, 1997), p. 117. 
do mágico- sí recurre profusamente al discurso metafórico y no produce, al contrario que las historias narradas, una dialéctica de relaciones complejas.

Ramos señala que hay que tener presente cómo la figura del Preste Juan surge en un contexto milenarista. Su origen está vinculado al centro mismo de la corte imperial germánica, como un poema propagandístico, para estimular el movimiento de los cruzados y en oposición ideológica tanto al Papa como a la Corte de Bizancio, y, por lo tanto, a la política teológica alternativa del Rey-Sacerdote.

\section{ALGUNAS COMPARACIONES Y DISERTACIONES}

No pretendo establecer una correspondencia clara entre cada una de las cuatro monografías, en relación a los conceptos de ortodoxia y heterodoxia. Se podría pensar que el estudio de Cátedra y el de Ramos se producen en ámbitos ligados a la ortodoxia - figuras religiosas y de santos reconocidas-, mientras que el de Prat estaría unido al heterodoxo mundo de las sectas religiosas. De igual manera, el estudio de Christian podría circunscribirse a un período emocionalmente intenso - el de las visiones - pero todavía no clasificado y por lo tanto no marcado por la ortodoxia o la heterodoxia.

Sin embargo, un análisis más detenido indica que el estudio de un santo aparentemente ortodoxo como San Segundo, en la actualidad patrón de la ciudad y compañero de Santa Teresa, aparece en la revolución de los Comuneros y es objeto de disputa clerical dentro de los cánones religiosos. Santa Barbada es una figura que aparece y desaparece en escenarios distintos, bien sea en el campo o en la ciudad y, cuando reaparece San Segundo, está en medio de una polémica que nunca termina. Como señala Cátedra, la "religión no sólo es un sistema de significados, rituales y símbolos que se refieren a fines últimos", sino que también es una "fuerza social y política". La invención de un santo expresa los deseos de la gente y su reconocimiento, o no, lo fija en la historia. El estudio del contexto en que este tipo de actitudes se produce, demuestra cómo son figuras de poder. $\mathrm{Y}$ es que muchas personas - tal como demuestra Cátedra- necesitaban estas figuras. La cofradía quería un santo que intercediera por ellos y los ayudara en su lucha contra el cabildo, la ciudad necesitaba un Varón Apostólico que diera nobleza a sus orígenes, los abulenses un capitán militar que les infundiera valor recordando sus antiguas gestas guerreras, la jerarquía eclesiástica un primer obispo y el rey, un administrador de la ciudad. 
A partir de aquí, quisiera hacer algunas anotaciones sobre la ortodoxia, la heterodoxia y el poder en la obra de los cuatro antropólogos. El estudio del portugués Manuel João Ramos es significativo a este respecto. La figura del Preste Juan de las Indias es una leyenda envuelta en un halo de reunificación entre hermanos de una misma familia - la cristiana-, separados por un destino incomprensible. El Preste Juan es un rey milenario, que vive en una torre que sube hasta el cielo - donde recibe alimento- y reina en un territorio que está situado en un lugar, más allá de las Indias, lleno de tesoros incalculables. Como en la mayoría de los actos de reunificación, el mundo futuro estará colmado de grandes dones tanto en el sentido económico como en el espiritual. La riqueza material está ejemplificada en este caso por la conquista de la ruta de las especias (la pimienta) y la espiritual con la toma de Jerusalén. Pero lo más importante -en términos del poder - es resaltar cómo una figura legendaria - la del Preste Juan - establece nexos entre diversas corrientes de opinión religiosa. Y es que en la ortodoxia existen diferentes clases.

De igual manera, el libro de William Christian sobre las visiones de Ezkioga pone de manifiesto cómo está presente, desde sus comienzos, una estructura de poder que puede legitimar un acto que ya ha cambiado la vida de muchas personas. En este caso es notable la oposición existente entre el "poder oficial" de la Iglesia —en tanto en cuanto no se pronuncia sobre el tema- y el poder de los videntes y sus promotores. Pero este poder oficial e institucionalizado - que se erige en ortodoxia- es, a la larga, el que decide la supervivencia de los actos de fe que son las visiones, consideradas heterodoxia, cuando no, herejía. La visión es una tierra de nadie, un proceso en el tiempo y puede llegar a ser ambas cosas: Ortodoxia y Heterodoxia, dependiendo de la sanción de la Iglesia y del contexto en que esta sanción se produzca.

Por su parte, María Cátedra muestra cómo la figura de San Segundo puede que no haya existido realmente. Y quizás su importancia no radique en la verdad histórica de la presencia del santo en los orígenes de Ávila, sino en la apropiación simbólica que de él hacen los estamentos ciudadanos, desde los revolucionarios hasta los más conservadores, para legitimar un orden que en algunos casos se desea cambiar. Cátedra expone los argumentos que, con el paso del tiempo, hacen de San Segundo y de Santa Paula Barbada unos "intermediarios" entre el reino terrenal y el celestial; una vez más, en el trasfondo está el problema del poder, es decir, de quiénes son los que crean y quiénes los que se apropian de los símbolos de ordenación social.

Joan Prat trata explícitamente el tema del poder, de la ortodoxia y la heterodoxia de las sectas religiosas. Estudiando una de estas posiciones 
-la heterodoxa-, Prat consigue centrar en el estigmatizado el comienzo de un proceso de reproducción simbólica que, con el transcurso del tiempo, puede llegar a ser la ortodoxia cultural dominante, como ha sucedido, entre otras religiones, con el cristianismo. Tal como postula Prat en el capítulo II de su libro, "Ortodoxia y herejía: las minorías religiosas en la historia", desde el comienzo de su andadura, el cristianismo se ha visto envuelto en debates para contener las diferentes opiniones que se desviaban del dogma que mantenía unida a la comunidad de fieles. La importancia que en su tiempo tuvieron diversas corrientes de pensamiento y acción religiosa - tales como las de los cátaros en el siglo XIII, los esenios al comienzo del cristianismo o los mormones en Estados Unidos- indica que siempre han existido disensiones compitiendo entre sí y contra el poder establecido para erigirse en depositarias de los ideales de redención y perfección espiritual. En el fondo, las que se enfrentan son concepciones diferentes del mundo, que se convierten en antagónicas al considerarse exclusivistas. Lo más interesante es, sin embargo, la similitud estructural que existe entre grupos religiosos en apariencia diferentes. Aparte de ese "aire de familia" indicado por Prat, existe una coincidencia notable en la apropiación simbólica de los orígenes que es lo que, a fin de cuentas, confiere una legitimidad indiscutible. Este mecanismo de identificación con una vuelta a los orígenes es lo que ha llevado a algunos autores a señalar el carácter conservador de ciertos movimientos religiosos que basan su estrategia de adaptación y supervivencia en una crítica feroz al sistema corrupto que caracteriza a la sociedad que les ha tocado vivir. La heterodoxia se convierte en ortodoxia cuando los grupos de inspiración religiosa son etiquetados o definidos como sectas o religiones. La heterodoxia es una sanción del poder.

La influencia que puede ejercer el medio externo en la aparición de nuevos movimientos religiosos parece estar fuera de toda duda. Incluso en algunas de las manifestaciones religiosas menos conocidas - como son las visiones-, Christian demuestra cómo se vieron "estimuladas" por la proclamación de la Segunda República y un consecuente aumento de las contradicciones entre la Iglesia y el Estado. En el caso de San Segundo, Cátedra describe cómo el santo resulta un símbolo del que se apropian los comuneros en un momento en que se está fraguando el movimiento revolucionario. Con él se cuenta con un "capitán" a la altura de la guerra que se iba a librar, nada menos que contra el rey. ¿Y qué decir del enorme influjo que ha tenido la leyenda del Preste Juan de las Indias en la búsqueda de un reino perdido y, sobre todo, en la ordenación cosmológica del mundo hasta entonces conocido? Quizás, con está cosmología, el mundo no sólo estaba ordenado en un complejo par de categorías opuestas 
-Oriente y Occidente- sino en dos mundos religiosos. Por ello, con los nuevos descubrimientos geográficos y la nueva interpretación de la historia bíblica, el Preste Juan se convierte en un símbolo con connotaciones negativas y heréticas, cambiando hasta el color de su piel: pasa del blanco puro al moreno y su reino ya no está situado en Asia sino en la Etiopía africana. Así, el ideario de una nación como Portugal se construye en torno a nuevos descubrimientos geográficos que liberan a sus protagonistas de las aventuras de sus predecesores. Al fin y al cabo el Preste Juan es el símbolo creado por una comunidad de creyentes que reflejan en él, como en un espejo, cuáles son las aspiraciones, deseos y dudas que motivan los actos que consideran supremos: los que los ponen en contacto con la divinidad.

Con el Preste Juan se vuelve a poner de manifiesto, al igual que ocurre con Santa Paula Barbada y San Segundo, lo desconcertante que pueden llegar a ser los símbolos. Para conocer su esencia es necesario establecer las dimensiones de carácter cultural, simbólico y político que acompañan a cada una de las figuras religiosas. Este marco de análisis - contextual - ofrece las bases para entender la complejidad de lo religioso.

El tema del poder subsume al campo y la ciudad. La relación de San Segundo y Santa Barbada con la ciudad es explícita. Son intermediarios que penetran de una manera simbólica en la ciudad amurallada por excelencia. Unen el campo y la ciudad en una estructura cultural que permanecerá latente en el ideario mental de los abulenses. Asimismo, los videntes de Ezkioga eran representantes, en su mayoría, del mundo rural del País Vasco, opuestos a las ciudades por sus aires de libertad e industrialización incipiente. Al manifestar con las visiones cuál era el mundo en que deberían vivir, la ciudad con sus peligros quedaba al margen de la nueva sociedad que postulaban. También los movimientos sectarios descritos por Prat tienen en la vida rural un ideal que no se suele llevar a la práctica. De hecho, la mayoría de sus acciones se realizan y reivindican en entornos urbanos, donde, a pesar de las apariencias, pueden desarrollarse con una mayor tranquilidad.

Por otro lado, no debe olvidarse la importancia que tiene la imposición del poder religioso institucionalizado en forma de normas de obligado y ortodoxo cumplimiento. A raíz del Concilio de Trento, la Iglesia católica fijó unas normas que marcaron un nuevo rumbo en el desarrollo de las devociones locales, y con ello un camino que indica, con la apropiación del signo, no sólo lo que es posible, sino también lo que es real.

De esta manera, es posible establecer varios puntos en común en las monografías - en apariencia dispares- de estos cuatro antropólogos. En 
principio, la religión no se puede estudiar fuera del contexto social y político. Por otro lado, vemos la existencia de diferentes niveles y clases de ortodoxia y heterodoxia, indicando con ello, cómo estos conceptos son susceptibles de ser analizados como productos y etiquetas del poder.

A partir del examen de cuatro monografías publicadas recientemente por antropólogos que trabajan en el ámbito ibérico, se estudian las distintas posibilidades de abordar el hecho religioso, con todas sus implicaciones sociales y políticas, haciendo especial hincapié en el análisis de las concepciones cambiantes de la ortodoxia o heterodoxia respecto de un hecho religioso preciso.

On the basis of an examination of four recent works by anthropologists who do research in Iberia, the author discusses the different ways of approaching religion and its social and political dimensions. He calls attention to the analysis of the changing concepts that ascribe a single religious phenomenon to orthodoxy or heterodoxy. 